Интернет-журнал «Науковедение» ISSN 2223-5167 http://naukovedenie.ru/

Том 7, №1 (2015) http://naukovedenie.ru/index.php?p=vol7-1

URL статьи: http://naukovedenie.ru/PDF/99TVN115.pdf

DOI: 10.15862/99TVN115 (http://dx.doi.org/10.15862/99TVN115)

УДК 15.2.19

Гон Хасон

Университет Кёнил

Республика Корея, Кенсан ${ }^{1}$

Доцент

E-mail: komgus@mail.ru

\title{
Необходимость в комплексном оборудовании видеосообщений и тушения при пожарах в Корее
}

1 712-701, Хаянып гамасилгил, д. 50 
Аннотация. В настоящей статье поясняется необходимость в комплексном оборудовании видеосообщений и тушения при пожарах в Республике Корее.

Интенсивность пожара во многом зависит от степени огнестойкости объектов и конструкций, горючести стройматериалов. Строительные и другие материалы по своему поведению в условиях высоких температур подразделяют на: несгораемые, трудносгораемые и сгораемые. От состава этих материалов, их горючести и зависит огнестойкость.

Благодаря моментальному видеосообщению пожар можно предотвратить значительно быстрее, если он возник. А так же можно определить достоверность пожара, ведь есть случаи, когда пожарная машина прибывает на место аварии из-за перебоя в работе оборудования автоматических сообщений и может не успеть потушить пожар вовремя в другом месте.

Ключевые слова: автоматическое устройство по оповещению при пожаре; устройство автоматического определения; комплексное оборудование видеосообщений и тушения при пожарах; многофункциональный прибор; устройство автоматического пожаротушения.

\section{Ссылка для цитирования этой статьи:}

Гон Хасон Необходимость в комплексном оборудовании видеосообщений и тушения при пожарах в Корее // Интернет-журнал «НАУКОВЕДЕНИЕ» Том 7, №1 (2015) http://naukovedenie.ru/PDF/99TVN115.pdf (доступ свободный). Загл. с экрана. Яз. рус., англ. DOI: 10.15862/99TVN115 
Настоящее исследование направлено на то, чтобы в целях придания эффективности оборудованию автоматической пожарной сигнализации обеспечить эффективное реагирование при возникновении пожаров путем проведения сравнения комплексного оборудования видеосообщений и тушения при пожарах, которое является более новым, точным и обладает усиленными функциями сообщений и профилактики по сравнению с прежним оборудованием автоматической пожарной сигнализации.

\section{1. Основы прежнего оборудования автоматической пожарной сигнализации}

Последовательность действий прежнего оборудования автоматической пожарной сигнализации: с оборудования автоматической пожарной сигнализации принимается сигнал о пожаре, заранее записанное на магнитофоне с интегральной схемой звуковое сообщение по сетям связи ТСОП (телефонные сети общего пользования) или CDMА (множественный доступ с кодовым разделителем) передается на номер 119, получается в ситуационном центре пожарной части, где отдается указание в пожарную часть об отправке пожарной команды [1]. Принятие сообщений о пожаре производится путем суждения о пожаре на основе слухового восприятия записанного голосового сообщения, при этом бывает нелегко определить ошибку в работе, а при возникновении помех в сети связи имеются затруднения и в слуховом восприятии [2]. С учетом нормативов безопасности оборудования автоматической пожарной сигнализации можно схематизировать последовательность действий, как она показана на следующем Рисунке 1.

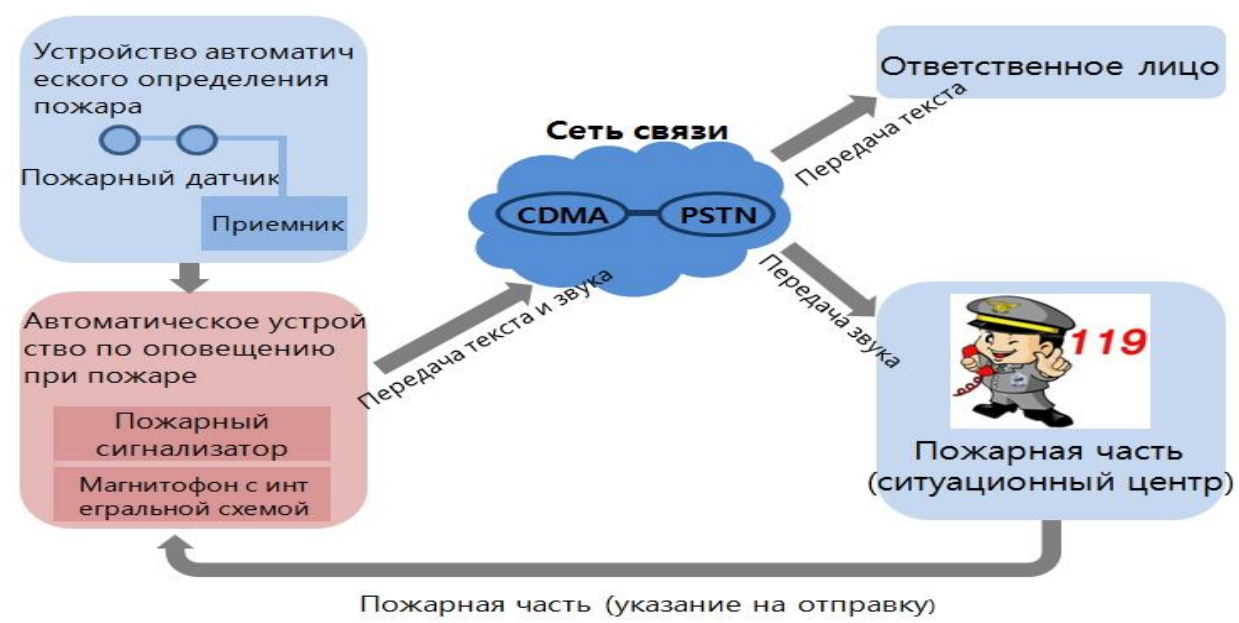

Pис. 1. Функииональная схема прежнего оборудования автоматической пожарной сигнализащии

\section{2. Основы комплексного оборудования видеосообщений и тушения при пожарах}

Предлагаемое в качестве новой системы оборудование автоматической пожарной сигнализации обладает функциями, позволяющими сообщать о пожарах при проводном и беспроводном подключении к Интернету и т. п. и состоит из комплексного оборудования видеосообщений и тушения при пожарах. При возникновении пожара на устройстве автоматического обнаружения пожара получается сигнал о пожаре, и когда этот сигнал передается на мультифункциональный прибор комплексного оборудования видеосообщений и тушения при пожарах, данный сигнал (с использованием корейского беспроводного Wi-Fi) посылается на беспроводную камеру и устройство автоматического пожаротушения. Получив сигнал о возникновении пожара, беспроводная камера производит съемку места пожара и 
посылает видеоизображение на мультифункциональный прибор [3]. После получения сигнала о пожаре срабатывает пожарный датчик устройства автоматического пожаротушения и производится тушение пожара на начальной стадии. Когда полученное на мультифункциональном приборе видеоизображение посредством ТCOП, WCDMA (широкополосного множественного доступа с кодовым разделением каналов), Интернета и других сетей связи посылается ответственному лицу и в ситуационный центр пожарной части, в пожарной части, получившей переданное звуковое сообщение и видеоизображение, уясняют ситуацию и высылают пожарную команду на место пожара. На Рисунке 2 схематически изображено комплексное оборудование видеосообщений и тушения при пожарах как новое оборудование автоматической пожарной сигнализации, сокращающее количество ошибок в работе.

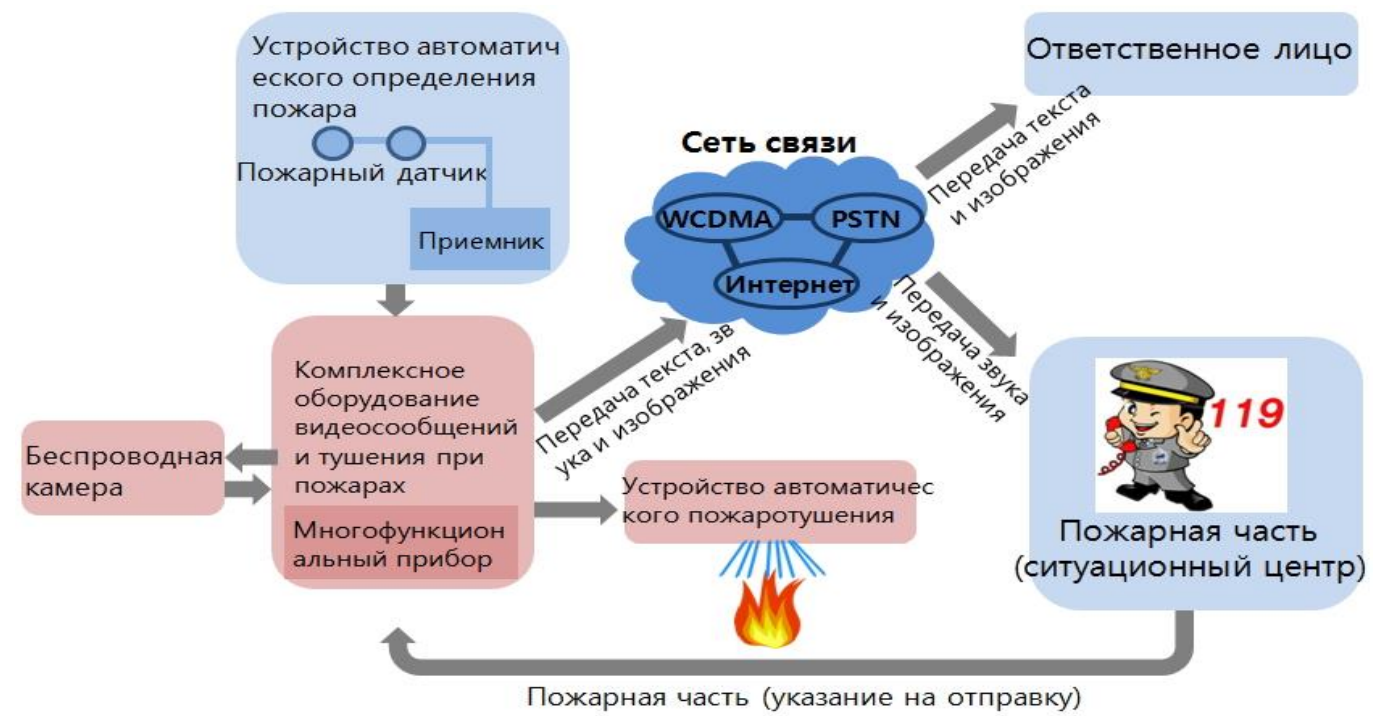

Pис. 2. Функииональная схема комплексного оборудования видеосообщений и тушения при пожарах

\section{3. Сравнительный анализ прежнего оборудования автоматической пожарной сигнализации и комплексного оборудования видеосообщений и тушения при пожарах}

По сравнению с прежним оборудованием автоматической пожарной сигнализации предлагаемое в качестве нового комплексное оборудование видеосообщений и тушения при пожарах наряду с текстовой и звуковой информацией предоставляет также видеоизображение и, будучи синхронизированным с устройством автоматического пожаротушения, обладает таким преимуществом, как тушение пожара на начальной стадии его возникновения, поэтому его можно назвать эффективным в точности обнаружения пожара и в раннем реагировании на пожар. Сравнительный анализ прежнего оборудования автоматической пожарной сигнализации и комплексного оборудования видеосообщений и тушения при пожарах представлено в Таблице 1 [2-5]. 
Таблица 1

Сравнительный анализ прежнего оборудования автоматической пожарной сигнализации и комплексного оборудования видеосообщений и тушения при пожарах

\begin{tabular}{|c|c|}
\hline $\begin{array}{c}\text { Прежнее оборудование автомати- } \\
\text { ческой пожарной сигнализации }\end{array}$ & $\begin{array}{c}\text { Комплексное оборудование видеосообщений } \\
\text { и тушения при пожарах }\end{array}$ \\
\hline $\begin{array}{l}\text { Автоматический сигнализатор пожа- } \\
\text { ра, приемник }\end{array}$ & $\begin{array}{l}\text { Автоматический сигнализатор пожара }+ \text { прием- } \\
\text { ник = Принимающе-передающий многофункци- } \\
\text { ональный прибор }\end{array}$ \\
\hline $\begin{array}{l}\text { Обнаружение пожара: Оборудование } \\
\text { автоматического обнаружения пожа- } \\
\text { ра }\end{array}$ & $\begin{array}{l}\text { Видеообнаружение пожара: Оборудование авто- } \\
\text { матического обнаружения пожара + беспровод- } \\
\text { ная камера }\end{array}$ \\
\hline $\begin{array}{l}\text { Способы передачи сигнала обнару- } \\
\text { жения пожара: CDMA, PSTN, TTS, } \\
\text { GIS, EDS }\end{array}$ & $\begin{array}{l}\text { Способы передачи видеосигнала обнаружения } \\
\text { пожара: WCDMA/LTE, PSTN, TTS, GIS, EDS }\end{array}$ \\
\hline Передача данных: текст, голос & Передача данных: текст, голос, видео \\
\hline $\begin{array}{l}\text { Объект передачи информации о по- } \\
\text { жаре: пожарная часть (голосовая ин- } \\
\text { формация), ответственное лицо (тек- } \\
\text { стовая информация) }\end{array}$ & $\begin{array}{l}\text { Объект передачи информации о пожаре: пожар- } \\
\text { ная часть (голосовая и видеоинформация), от- } \\
\text { ветственное лицо (текстовая и видеоинформа- } \\
\text { ция) }\end{array}$ \\
\hline
\end{tabular}


4. Промышленные, технические и экономические характеристики комплексного оборудования видеосообщений и тушения при пожарах

В Таблице 2 рассматриваются промышленные, технические и экономические характеристики комплексного оборудования видеосообщений и тушения при пожарах[4-10].

Таблица 2

Промышленные, технические и экономические характеристики

\begin{tabular}{|c|c|c|}
\hline $\begin{array}{c}\text { Промышленные характери- } \\
\text { стики }\end{array}$ & $\begin{array}{c}\text { Технические характе- } \\
\text { ристики }\end{array}$ & $\begin{array}{c}\text { Экономические характери- } \\
\text { стики }\end{array}$ \\
\hline $\begin{array}{l}\text { (1) Автоматический приемник } \\
\text { со стабильными интегриро- } \\
\text { ванными комплексными ин- } \\
\text { формационными технология- } \\
\text { ми, позволяющий точно опо- } \\
\text { знавать и различать возникно- } \\
\text { вение пожара на начальной } \\
\text { стадии } \\
\text { (2) Приемник с автоматиче- } \\
\text { ской отправкой сигнала о по- } \\
\text { жаре, в котором разрешены } \\
\text { проблемы надежности и } \\
\text { ошибки, вызванные распозна- } \\
\text { ванием в прежних системах } \\
\text { посредством просто датчиков } \\
\text { (3) Тушение пожара на } \\
\text { начальной стадии с миними- } \\
\text { зацией производственных } \\
\text { аварий, человеческих жертв и } \\
\text { имущественного ущерба по- } \\
\text { средством эпохальных усо- } \\
\text { вершенствований } \\
\text { (4) Система профилактики, } \\
\text { оповещения и тушения пожа- } \\
\text { ра на начальной стадии с ин- } \\
\text { тегрированными комплексны- } \\
\text { ми многоцелевыми информа- } \\
\text { ционными технологиями, ко- } \\
\text { торые также делают возмож- } \\
\text { ной функцию профилактики }\end{array}$ & $\begin{array}{l}\text { (1) Максимальное повы- } \\
\text { шение достоверности } \\
\text { определения и распозна- } \\
\text { вания ошибочного опре- } \\
\text { деления пожара на осно- } \\
\text { ве прежних термодатчи- } \\
\text { ков и датчиков дыма за } \\
\text { счет наблюдения с по- } \\
\text { мощью камеры (предот- } \\
\text { вращение ненужных вы- } \\
\text { ездов пожарных команд) } \\
\text { (2) Максимальное повы- } \\
\text { шение достоверности } \\
\text { определения и распозна- } \\
\text { вания пожаров за счет } \\
\text { добавления к прежним } \\
\text { текстовому и голосовому } \\
\text { форматам функции ви- } \\
\text { деоданных } \\
\text { (3) Возможность быстро } \\
\text { передавать в режиме ре- } \\
\text { ального времени в ситу- } \\
\text { ационный центр пожар- } \\
\text { ной части больших мас- } \\
\text { сивов данных за счет ис- } \\
\text { пользования сетей связи } \\
3 G \text { и 4G, а также GРS, } \\
\text { возможность принятия } \\
\text { мер и более быстрое ав- } \\
\text { томатическое тушение } \\
\text { пожара на начальной } \\
\text { стадии за счет точного } \\
\text { определения местополо- } \\
\text { жения }\end{array}$ & $\begin{array}{l}\text { 1) Минимизация имуще- } \\
\text { ственного ущерба за счет } \\
\text { усовершенствования распо- } \\
\text { знавания ошибок, определе- } \\
\text { ния, распознавания и туше- } \\
\text { ния пожара на начальной } \\
\text { стадии, минимизация иму- } \\
\text { щественного ущерба и чело- } \\
\text { веческих жертв за счет точ- } \\
\text { ности подавления пожара, } \\
\text { максимизация экономическо- } \\
\text { го волнового эффекта за счет } \\
\text { активизации монтажа внутри } \\
\text { страны и за рубежом прием- } \\
\text { ников с автоматической по- } \\
\text { жарной сигнализацией с ин- } \\
\text { тегрированными комплекс- } \\
\text { ными информационными } \\
\text { технологиями } \\
\text { (2) Упрощение монтажа и } \\
\text { экономия монтажных расхо- } \\
\text { дов за счет беспроводного } \\
\text { оборудования автоматическо- } \\
\text { го пожаротушения и сигна- } \\
\text { лизации } \\
\text { (3) Создание круглосуточной } \\
\text { системы техобслуживания и } \\
\text { управления за счет ком- } \\
\text { плексной централизованной } \\
\text { системы управления, пожар- } \\
\text { ной безопасности, предот- } \\
\text { вращения аварий, оповеще- } \\
\text { ния, профилактики и обеспе- } \\
\text { чения безопасности }\end{array}$ \\
\hline
\end{tabular}

Источники: Обобщение работ: Ким Джан Вон (2013), И Сан Син и др. (2008), И Бон Соб и др, (2012), Ким Ён Дон и др. (2006), Юн $\ddot{Е}$ Хо и др. (2008), Чан Пхён Хун и др. (2007), Ким Сон Чхан (2012). 
В настоящем исследовании в сопоставлении с прежним оборудованием автоматической пожарной сигнализации в целях точности обнаружения пожаров и эффективности раннего реагирования на пожары было предложено комплексное оборудование видеосообщений и тушения при пожарах, ожидаемый эффект которого, вопервых, дает возможность путем предоставления информации, позволяющей с помощью видеоизображения отслеживать обстановку на месте в режиме реального времени, предотвращать ненужные выезды, обусловленные ошибками в работе прежнего оборудования автоматических сообщений при пожарах. Во-вторых, благодаря раннему тушению при возникновении пожара можно сдерживать распространение пожара до прибытия пожарной команды. В-третьих, беспроводная комплексная система пожаротушения с использованием информационных технологий и видеоизображения является экономичной, так как не требует дополнительных строительных работ.

\section{ЛИТЕРАТУРА}

1. Корейское Управление законодательства. "Чадон хваджэ сокпо сольбиый хваджэ анджон киджун" ("Нормативы пожарной безопасности оборудования автоматической пожарной сигнализации"), ст. 3, ст. 4, Сеул: Корейское Управление законодательства. 2015. - 1 с.

2. $\quad$ И Гван Сик, Ким Джун Ён, Ю Сан Сик, Ким Ын Сик. "Internet ыль иёнхан чадон хваджэ сокпо систем" ("Система автоматической пожарной сигнализации с использованием Интернета"), Сборник статей научной конференции Корейского научного общества безопасности. 1998. - 235 с.

3. Пак Се Хва. "Юбикхвотхосы хвангёныль вихан тхонхапхён хваджэ сусинги кэбаре гванхан ёнгу" ("Исследование разработки приемников пожарных сигналов комплексного типа для универсальных сред"), "Журнал Корейского института пожарной науки и инженерии", т. 24, № 1. 2010. - С. 25-26.

4. Ким Джан Вон. "CCD кхамера ёнсаныль иёнхан сыматхы хваджэ ёнсан инсик систем" ("Система "умного" распознавания изображений пожара и использованием изображения с камеры на ПЗС"), "Журнал Корейского института пожарной науки и инженерии", т. 27, № 6. 2013. - 81 с.

5. И Сан Син, Ким Джэ Хо, Вон Гван Хо, Ким Джун Хван. "Мусон имиджи сенсо нетхывокхы хвангёныль вихан хёюльчогин ёнсан чонбо чонсон систем" ("Эффективная система передачи видеоинформации для беспроводных сетей датчиков изображений"), "Журнал Корейского института пожарной науки и инженерии", т. 35, № 3. 2008. - С. 207-214.

6. И Бон Соб, Квак Тон Гёль, Чон До Ён, Чхон Дон Джин. "Янбанхян тхонсини канынхан чадон хваджэ тхамджи сольби (Р-хён 1-гып сусинги) ый сольге мит тонджак тхыксоне гванхан ёнгу" ("Исследование конструкции и рабочих характеристик оборудования автоматического обнаружения пожара с возможностью двусторонней связи (приемника 1-го уровня типа "Р")"), "Журнал Корейского научного общества электричества", т. 61, № 2. 2012. - С. 347-353.

7. Ким Ён Дон, О Гым Гон, Кан Вон Чхан. "CAN тхонсин кибан чадон хваджэ тхамджи сольбие гванхан ёнгу" ("Исследование оборудования автоматического обнаружения пожара на основе связи в сети с абонентским доступом", "Журнал Корейского научного общества осветительного электрического оборудования", т. 20, № 2). 2006. - С. 50-59. 
8. Ю Ён Хо, Квон О Сан, Ю Джи О, Хван Бён Чхоль (2010), "Ёнсан юго камджиги соннын пхёнкарыль вихан сирхомджок ёнгу" ("Экспериментальное исследование для оценки характеристик видеодатчиков для определения происшествий", Сборник статей осенней научной конференции Корейского научного общества пожаротушения). 2010. - С. 155-188.

9. Чан Пхён Хун, Пак Кён Бин, Чо Гон Рэ, Ким Джон Гвон, И Ю Джун. "Собан робот вонкёк чеорыль вихан ёнсан канхва кибоп" ("Методы усиления изображения для дистанционного управления пожарными роботами"), Сборник статей осенней научной конференции Корейского научного общества пожаротушения. 2007. - С. 219-224.

10. Ким Сон Чхан. "Хваджэён ёльхвасан кхамераый ёнсан пхохва тхыксон пхёнка" ("Оценка характеристик насыщенности изображения в пожарной термографической камере", "Журнал Корейского института пожарной науки и инженерии", т. 26, № 2). 2012. - С. 69-74.

Рецензент: Ко Ен Чоль, профессор кафедры социально экономических инноваций, к.п.н., НП ВПО Институт международных социально-гуманитарных связей. 
Kong Hasung

Kyungil University

Republic of Korea, Kyungsan city

E-mail: komgus@mail.ru

\section{The necessity of automatic image notification \& fire extinguishing system in Korea}

Annotation. In this article explains the need for an integrated hardware video messaging and extinguishing fires in the Republic of Korea.

The intensity of the fire depends on the degree of fire resistance of objects and structures, the flammability of materials. Constructions and other materials in their behavior at high temperatures are divided into: fireproof, combustible and nonflammable. On the composition of these materials depends on their fire resistance and combustibility.

Thanks a momentary video message fire can be prevented much faster if it arose. And so it is possible to determine the accuracy of the fire, because there are cases when a fire truck arrives at the scene of an accident due to equipment failure in the automatic messages and can't be able to extinguish the fire in time in elsewhere.

Keywords: automatic fire notification system; automatic fire detection system; automatic image notification \& fire extinguishing system; image \& fire detect receiving system; automatic fire extinguishing system. 


\section{REFERENCES}

1. Ministry of government legislation of Korea. "National Fire Safety Codes of Automatic Fire Notification System", section 3 \& 4, Seoul: Ministry of government legislation of Korea, 2015. - $1 \mathrm{~s}$.

2. Lee Kwang Sik, Kim Jun Young, Yu Sang Sik, Kim Eung Sik(1998), “Automatic Fire Notification System Using Internet", Proceedings of the Korean Institute of Industrial Safety Conference, 1998. - $235 \mathrm{~s}$.

3. Park Se Hwa (2010), "A Study on the Development of Integrated Type Fire Alarm Control Panel for Ubiquitous Environment", Journal of Korean Institute of Fire Science \& Engineering, Vol.24, No.1, 2010. - S. 25-26.

4. Kim Jang Won(2013), "Smart Fire Image Recognition System using Charge-Coupled Device Camera Image", Journal of Korean Institute of Fire Science \& Engineering, Vol.27, No.6, 2013. - $81 \mathrm{~s}$.

5. Lee Sang shin, Kim Jae ho, Won Kwang ho, Kim Joong Hwan. "An Effcient Image Information Transfer System for Wireless Image Sensor Network Environments", Journal of The Korea Information Science, Vol.35, No.3, 2008. - S. 207-214.

6. Lee Bong Seob, Kwak Dong Kurl, Jung Do Young, Cheon Dong Jin. “A Study on Design and Operation Performance of Automatic Fire Detection Equipment(P-type One-class Receiver) by Bidirectional Communication", The Transactions of the Korean Institute of Electrical Engineers, Vol.61, No.2, 2012. - S. 347-353.

7. Kim Young Dong, Oh Guem Koh, Kang Won Chan. "A Study of Automatic Fire Detection Installation based CAN Comunnication", Journal of the Korean Institute of Illuminating and Electrical Installation Engineers, Vol.20, No.2, 2006. - S. 50-59.

8. Yoo Yong Ho, Kweon Oh Sang, Yoo Ji Oh, Hwang Byoung Chul. "An Experiment Study on Performance Evaluation of the Video Incident Detection System", Proceedings of Autumn Annual Conference, Korean Institute of Fire Science \& Engineering, 2010. - S. 155-188.

9. Chang Pyung Hun, Park Kyung Bin, Gun Rae Cho, Kim Jong Kwon, Lee Woo Jun. "A Vision Enhancement Technique for Remote Control of Fire Fighting Robots", Proceedings of Autumn Annual Conference, Korean Institute of Fire Science \& Engineering, 2007. - S. 219-224.

10. Kim Sung Chan. "Performance Evaluation of Image Saturation of Thermal Imaging Camera for the Fire Service", Journal of Korean Institute of Fire Science \& Engineering, Vol.26, No.2, 2012. - S. 69-74. 